\title{
TO EVALUATE THE EFFECTIVENESS OF PATIENT EDUCATION ON CLINICAL OUTCOME IN HOSPITALIZED DIABETIC PATIENTS B Y CLINICAL PHARMACIST
}

\author{
*Hinchageri SS ${ }^{1}$, Patil Neelkanthreddy ${ }^{1}$, Devar Sanjay ${ }^{2}$, Biradar BS ${ }^{2}$, Hinchageri Rajeshree ${ }^{2}$ \\ ${ }^{1}$ Department of Pharmacy Practice, Basaveshwar Teaching and General Hospital, HKES's College of Pharmacy, Sedam Road, \\ Gulbarga- 585105 Karnataka, India \\ ${ }^{2}$ BVVS's, H.S.K. College of Pharmacy, Bagalkot, Karnataka, India \\ *Corresponding Authors Email: shivanandhinchageri95@gail.com
}

Received 09 May 2012; Review Completed 07 June 2012; Accepted 25 June 2012, Available online 15 July 2012

\begin{abstract}
:
The prevalence of the diabetes is increasing particularly in developing countries. Diabetes is a chronic illness that requires continuous medical care and patient education in order to prevent microvascular and macrovascular complications. Diabetes education is the cornerstone of diabetes care. Patients need education about diet, exercise, weight control, blood glucose monitoring, use of medications and adherence, foot and eye care. The objective of the study is to evaluate the effectiveness of patient education on clinical outcome of hospitalized diabetic patients and to assess the baseline knowledge of the patient towards diet, lifestyle modification, disease, medication and medication adherence. A hospital based prospective study conducted at Inpatient Department of Medicine. The result shown that baseline knowledge of the patient towards diet, disease and medication adherence was found to be very low. The lab parameters were observed at baseline and further for two fallow ups, that shows statistically significant improvement from baseline to first and second follow up. The positive improvement in lab parameter as HbAlc, FBS, PPBS, blood pressure (clinical outcome), due to an improvement in patient's knowledge, dietary modification, lifestyle changes, understanding of disease, medication and improved medication adherence after providing patient education. The study further suggest, patient education by care providers is essential to encourage the patients for regular physical activity, improve dietary habits, to increase medication knowledge and adherence, which helps for improving clinical outcome in diabetic patients as well as other chronic diseases.

Key Words: Patient education, Clinical outcome, lab parameters, medication adherence, lifestyle modification.
\end{abstract}

\section{INTRODUCTION:}

The prevalence of the diabetes is increasing particularly in developing countries. Estimate of global diabetes prevalence predict $6.4 \%$, affecting 285 million adults in 2010, and will increase to $7.7 \%$ and 439 million adults by 2030. India has largest number of diabetic patients in the world. The International Diabetes Federation (IDF) reported that the total number of diabetic subjects in India is 41 million in 2006 and that this would rise to 70 million by the year 2025. Increased prevalence in India is attributed to the lifestyle transition coupled with urbanization, industrialization and lifestyle changes. ${ }^{1}$

Diabetes is a chronic illness that requires continuous medical care and patient education in order to prevent microvascular and macrovascular comp lications. The risk of heart disease and stroke is two to four folds greater among people with diabetes. ${ }^{2}$ The complications of diabetes is to a large extent the consequence of macrovascular (coronary artery disease, peripheral vascular disease, and atherosclerosis) and microvascular (like retinopathy, neuropathy, and nephropathy) complications of the disease. ${ }^{3,4}$

Diabetes care aims at improving the quality of life of diabetic patients through good glycemic control, control of risk factors, lifestyle modification, prevention of complications and diabetes education. Diabetes education is the cornerstone of diabetes care. ${ }^{5}$ Diabetes knowledge may enhance the ability of diabetic patients to cope and adjust to their illness. Similarly, patients with greater understanding and knowledge of their medications have (c) 2011, JDDT. All Rights Reserved been shown to have better glycaemic control. On the other hand, poor knowledge of diabetes is associated with increased rate of hospitalization for unstable diabetes. Patients need to make informed decisions about diet, exercise, weight control, blood glucose monitoring, medication usage, foot and eye care, and control of mac rovascular risk factors. ${ }^{6}$

Patient counseling is defined as providing medication related information orally or in written form to the patient or their representatives, on topics like direction of use, advice on side effects, precautions, storage, diet and life style modification. ${ }^{7}$ Patient's knowledge of medication use is of vital importance in the treatment success. The clear understanding of diagnostic and treatment advice correlates with adherence, which in turn leads to achievement of health. ${ }^{8}$ One study showed that intensive diabetes education and care management can improve the patient outcomes, glycemic control and quality of life in patients with diabetes mellitus. ${ }^{9}$ The reasons for patients not achieving treatment goals may include underutilization of medications, poor medication adherence, under appreciation of goal attainment importance, or lack of goal knowledge. ${ }^{10}$

The role of pharmacists has changed dramatically over the past 30 years. Traditionally, pharmacists have been viewed as individuals who dispense medications to the public. The concept of pharmacy practice has gradually changed from a product oriented activity to a patient-oriented one. 
Pharmacists are now becoming indispensable in monitoring drug therapy in institutional settings. ${ }^{\mathbf{1 1}}$

The goals of the Diabetic Education Program are to provide the highest quality education, medical care, and ongoing cultural and emotional support for all diabetics. ${ }^{\mathbf{1 2}}$ Diabetes education has been an essential component of diabetes management since the 1930s and is increasingly recognized as an integral part of chronic disease management. ${ }^{13}$ India is currently lacking structured education and information programme regarding diabetes. Obtaining information on level of awareness about diabetes is the first step in formulating a prevention programme. But a less attempts are done to assess the educational need of the patients and studies are mostly from urban area. The lower awareness must be present in rural area, very few of them are diagnosed and on regular treatment. ${ }^{14}$

So in present study we had assessed the existing knowledge of diabetic patient and further evaluated the effectiveness of patient education about diet, lifestyle modification, disease, medication and medication adherence, on clinical outcome in hospitalized diabetic patients. The objective of study includes: 1 . To evaluate the effectiveness of patient education on clinical outcome of hospitalized diabetic patients. 2. To assess the baseline knowledge of the patient towards diet, lifestyle modification, disease, medication and medication adherence.

\section{METHODOLOGY:}

\section{Study Site:}

The study was carried out at Department of Medicine, H.K.E.S's Basaveshwar Teaching and General Hospital, Gu lbarga, Karnataka, India.

\section{Study design:}

A hospital based prospective study.

\section{Study duration:}

The study was carried out for a period of 6 months, from May 2010 to October 2010.

\section{Study criteria:}

The Diabetic patients visiting In patients Department of Medicine were enrolled in to the study after obtaining their verbal consent and by considering following inclusion and exclusion criteria.

\section{Inclusion criteria:}

Patients with age of above 18 years and of either sex.

$>$ Patients having $\mathrm{HbA}_{1} \mathrm{C}$ above $7.5 \%$

Patients diagnosed with Diabetes Mellitus and on treatment at least since last 1 year.

\section{Excl usion criteria:}

Patients newly diagnosed with Diabetes Mellitus.

Patients not willing to participate in the study.

$>$ Patients with pregnancy and lactating women.

\section{Source of data:}

Case Sheets and treatment charts of Inpatients.

Laboratory reports of the Patients.

\section{Study procedure:}

Those patients, who met the inclusion criteria, were enrolled at the time of discharge into the study after obtaining their verbal consent. Patient demographics like age, family history, dietary habits, past and present medical and medication history were collected.

Patient Education and Follow up: The baseline patient knowledge regarding diet, lifestyle modification, disease, medication and medication adherence were assessed. Based on patient's baseline knowledge and educational profile the patients educated and also provided information leaflet covering all essential points. The baseline glycemic lab parameters glycosylated hemoglobin (HbA1c), fasting blood glucose (FBS), postprandial blood glucose(PPBS), blood pressure (BP), were obtained from laboratory reports.

The patients were asked to come back for follow-up once in 45 days, for a period of 3 months. During $1^{\text {st }}$ follow-up, FBS, PPBS and BP of the patients was noted. During $2^{\text {nd }}$ follow-up, HbA1c, FBS, PPBS and BP of the patients was noted. The data collected was statistically analy zed by Chisquare test and column statistic.

\section{RES ULTS:}

Table 1: De mographic details of the Patient

\begin{tabular}{|c|c|c|}
\hline S.N. & Particulars & $\begin{array}{l}\text { No. of Patients } \\
(n=121)\end{array}$ \\
\hline 01 & $\begin{array}{l}\text { Gender } \\
\text { Male } \\
\text { Female }\end{array}$ & $\begin{array}{l}86(71.1 \%) \\
35(28.9 \%)\end{array}$ \\
\hline 02 & $\begin{array}{l}\text { Age (in years) } \\
21-40 \\
41-60 \\
61-80 \\
\square 80\end{array}$ & $\begin{array}{l}07(5.8 \%) \\
56(46.3 \%) \\
54(44.6 \%) \\
04(3.3 \%)\end{array}$ \\
\hline 03 & $\begin{array}{l}\text { Education } \\
\text { Illiterate } \\
\text { School } \\
\text { Pre-University } \\
\text { University }\end{array}$ & $\begin{array}{l}53(43.8 \%) \\
46(38 \%) \\
12(9.9 \%) \\
10(8.26 \%)\end{array}$ \\
\hline 04 & $\begin{array}{l}\text { Duration of DM (in years) } \\
1-5 \\
6-10 \\
11-15 \\
\square 16\end{array}$ & $\begin{array}{l}39(32.2 \%) \\
44(36.4 \%) \\
26(21.5 \%) \\
12(9.9 \%)\end{array}$ \\
\hline 05 & $\begin{array}{l}\text { Family History } \\
\text { Yes } \\
\text { No }\end{array}$ & $\begin{array}{l}41(33.9 \%) \\
80(66.1 \%)\end{array}$ \\
\hline 06 & $\begin{array}{l}\text { Diet } \\
\text { Veg } \\
\text { Non-Veg } \\
\text { Mixed }\end{array}$ & $\begin{array}{l}33(27.3 \%) \\
23(19 \%) \\
65(53.7 \%)\end{array}$ \\
\hline 07 & $\begin{array}{l}\text { Complications } \\
\text { Retinopathy } \\
\text { Neuropathy } \\
\text { Cardiovascular } \\
\text { Cerebrovascular } \\
\text { Cardio + Cerebrovascular } \\
\text { Renal + Cardiovascular }\end{array}$ & $\begin{array}{l}02(1.65 \%) \\
02(1.65 \%) \\
64(52.9 \%) \\
06(4.95 \%) \\
08(6.6 \%) \\
10(8.3 \%)\end{array}$ \\
\hline
\end{tabular}


A total of 134 Diabetes Mellitus II patients were enrolled into the study, out of which, 121 patients have completed the study and remaining 13 patients did not turn up for the follow up. The data of only those patients who completed the study were analyzed. The demographic details of the enrolled patients shown in table 1 .

The prescription detail of the patients shows that, $37.2 \%$ of the patient $\mathrm{s}$ on combination of Insulin and OAD's. The prescription details of the patients shown in table 2 .

The patient's baseline knowledge was assessed towards diet, lifestyle modification, disease, medication and medication adherence. The details of the baseline knowledge shown in table 3.

Table 2: Prescription details of the patient:

\begin{tabular}{|l|l|l|}
\hline S.N. & Therapy & $\begin{array}{l}\text { No. of Patients } \\
(\mathbf{n = 1 2 1})\end{array}$ \\
\hline $\mathbf{0 1}$ & Oral Antidiabetic Therapy & \\
& (OAD's) & $32(26.4 \%)$ \\
& Monotherapy & $65(53.7 \%)$ \\
& Two-drug Therapy & $24(19.8 \%)$ \\
& Three- Drug Therapy & \\
\hline 02 & Insulin Therapy + OAD's & $45(37.2 \%)$ \\
\hline
\end{tabular}

Table 3: Details of the baseline knowledge of the patient

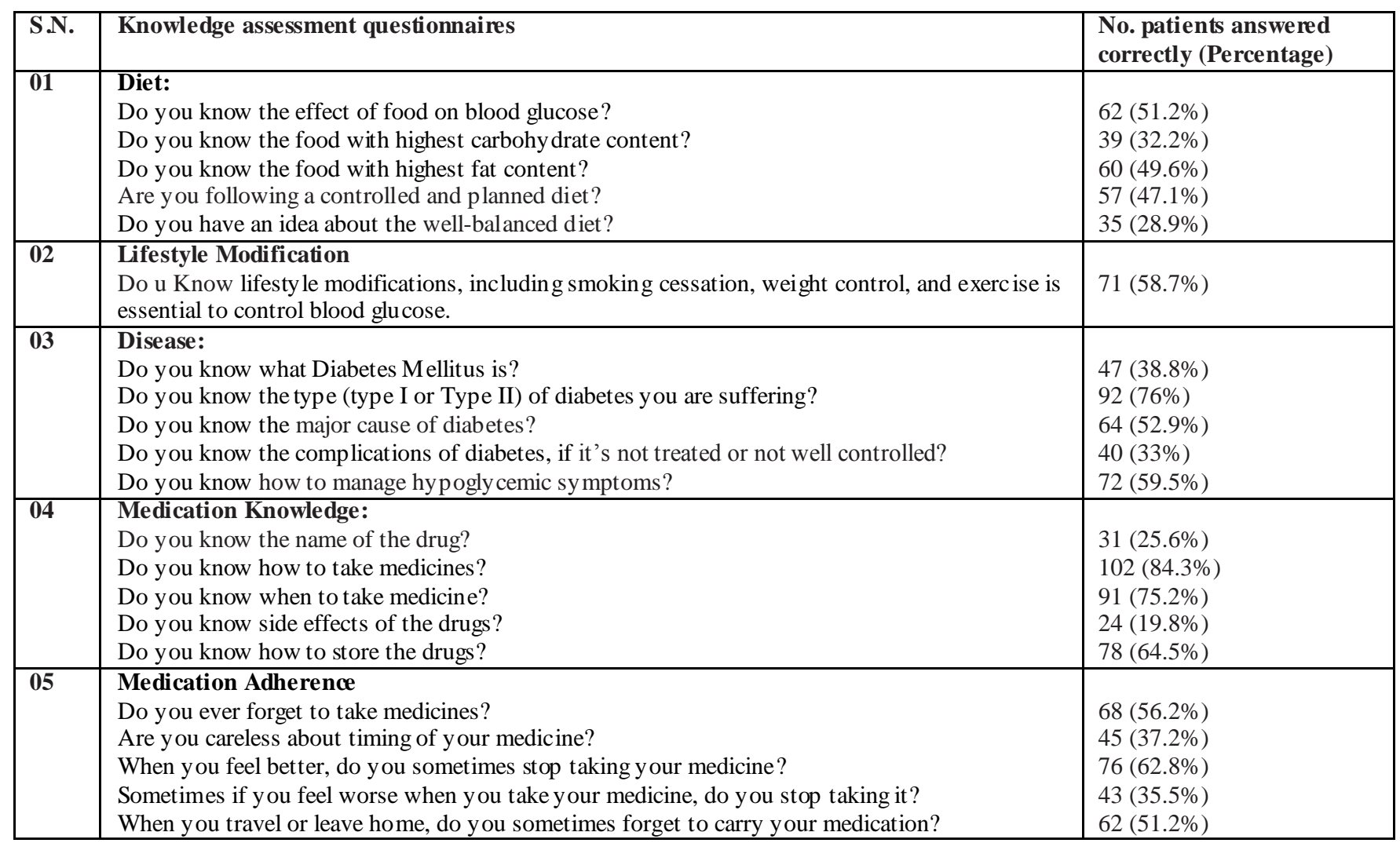

Assessment of patient's FPG level from baseline to first follow up showed a mean increase in $183.5 \pm 31.54$ and $\mathrm{P}<$ 0.05 which is statistically significant. The patient's PPG level from baseline to first follow up showed a mean increase in $259.8 \pm 42.78$ and $\mathrm{P}<0.05$ which is statistically significant. The patient's BP (Systolic) level from baseline to first follow up showed a mean increase in $131.6 \pm 2.05$ and $\mathrm{P}<0.05$ which is statis tically significant. The patient's BP (Diastolic) level from baseline to first follow up showed a mean increase in $85.4 \pm 0.79$ and $\mathrm{P}<0.05$ which is statistically significant. The details of lab data Average baseline to Average I follow up shown in table 4.

Table 4: Details of lab data Average baseline to Average I follow up

\begin{tabular}{|c|c|c|c|c|}
\hline Parameter & Average Baseline & Average I Follow up & Mean \pm SD \\
\hline FPG & 205.8 & 161.2 & $183.5 \pm 31.54$ \\
\hline PPG & 290.9 & 229.5 & $259.8 \pm 42.78$ \\
\hline BP (Sy stolic) & 133.2 & 130.1 & $131.6 \pm 2.05$ & P $<0.05$ \\
\hline BP (Diastolic) & 86.07 & 84.88 & $P<0.05$ & $85.4 \pm 0.79$ \\
\hline
\end{tabular}




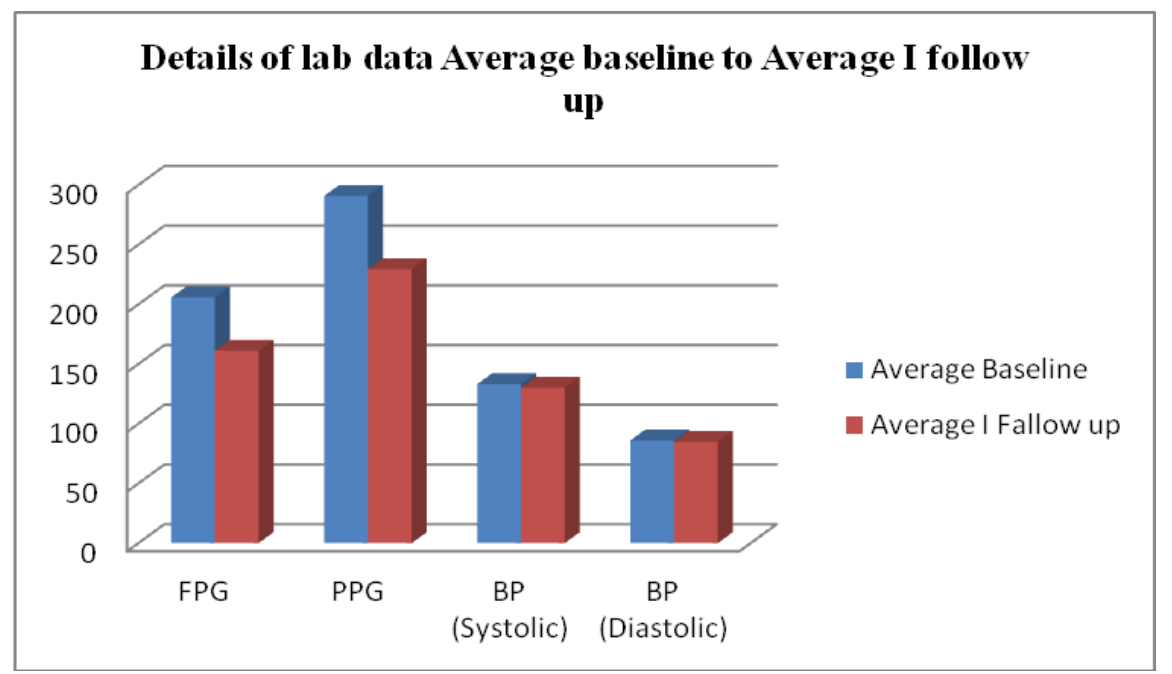

Figure 1: Details of lab data Average baseline to Average I follow up

Ass essment of patient's FPG level from baseline to second follow up showed a mean increase in $160.3 \pm 64.42$ and $\mathrm{P}<$ 0.05 which is statistically significant. The patient's PPG level from baseline to second follow up showed a mean increase in $242.6 \pm 68.31$ and $P<0.05$ which is statistically significant. The patient's HbAlc level from baseline to second follow up showed a mean increase in $9.57 \pm 0.78$ and $\mathrm{P}<0.05$ which is statistically significant. The patient's
BP (Systolic) level from baseline to second follow up showed a mean increase in $130.7 \pm 3.53$ and $\mathrm{P}<0.05$ which is statistically significant. The patient's BP (Diastolic) level from baseline to second follow up showed a mean increase in $84.9 \pm 1.16$ and $\mathrm{P}<0.05$ which is statistically significant. The Details of lab data Average baseline to Average II follow up shown in table 5.

Table 5: Details of lab data Average baseline to Average II follow up

\begin{tabular}{|c|c|c|c|c|}
\hline Parameter & Average Baseline & Average II Follow up & Mean \pm SD & P- Value \\
\hline FPG & 205.8 & 114.7 & $160.3 \pm 64.42$ & $\mathrm{P}<0.05$ \\
\hline PPG & 290.9 & 194.3 & $242.6 \pm 68.31$ & $\mathrm{P}<0.05$ \\
\hline HbA1c & 10.13 & 9.02 & $9.57 \pm 0.78$ & $\mathrm{P}<0.05$ \\
\hline BP (Systolic) & 133.2 & 128.2 & $130.7 \pm 3.53$ & $\mathrm{P}<0.05$ \\
\hline BP (Diastolic) & 86.07 & 83.79 & $84.9 \pm 1.16$ & $\mathrm{P}<0.05$ \\
\hline
\end{tabular}

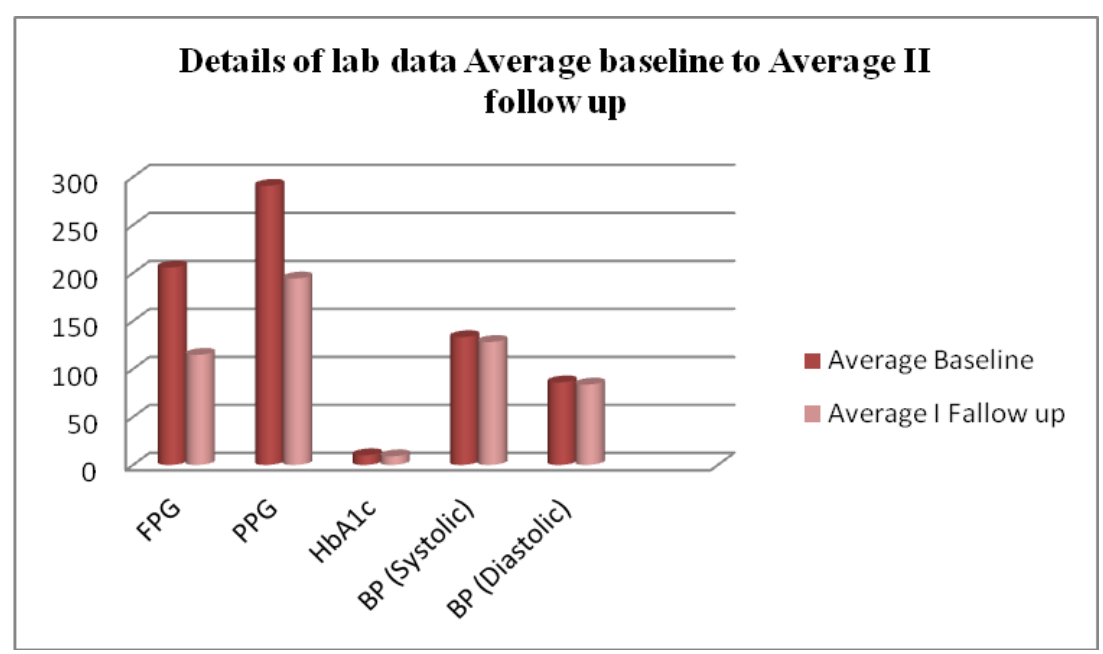

Figure 2: Details of lab data Average baseline to Average II follow up

\section{DISCUSS ION:}

The management of Diabetes Mellitus not only requires the prescription of the appropriate nutritional and pharmacological regimen by the physician but also intensive patient education and counseling. Diabetes is a chronic disease with altered carbohydrate, lipid and protein metabolism. The chronic diabetic complications are known to affect the quality of life of patients. Various factors like understanding of the patients about their disease, socioeconomic factors, dietary regulation, self monitoring of blood glucose are known to play a vital role in diabetes management. ${ }^{7,15}$

In the present study shows that, number of male patients visiting to Inpatient department found to be more than the female might be due to uncontrolled diet and lack of lifestyle modification. The study observed that, more than 
$50 \%$ of patients having a cardiovascular complication mainly hypertension and ischemic diseases, may be due to lack of knowledge over diabetic complication, uncontrolled diet and lack of lifestyle modification. The prescription detail of the patients shows that, $37.2 \%$ of the patient s on combination of Insulin and OAD's. Here the blood glucose not controlled only with OAD's, so the patients have been added with insulin therapy along with OAD's. The baseline knowledge of the patient towards diet, disease and medication adherence was found to be very low because most of the patient visiting to the Basaveshwar teaching and general hospital is from rural area where more illiterateracy and lack of patient educators. The lab parameters were observed at baseline and further for two fallow ups, that shows statistically significant improvement from baseline to first and second follow up. The positive improvement in lab parameter (clinical outcome) due to improvement in patient's knowledge, dietary modification, lifestyle changes, understanding of disease, medication and improved medication adherence after providing patient education.

The study further suggest, patient education by care providers such as physicians, pharmacist and nursing staff

\section{REFERANCE:}

1. Padma K, Bele SD, Bodhare TN, Valsangkar S. Evaluation of knowledge and self care practices in diabetic patients and their role in disease management. National Journal of Community Medicine, Jan-March 2012;3(1):3-6.

2. Centers for Disease Control and Prevention. National diabetes fact sheet: general information and national estimates on diabetes in the United States, 2005. Atlanta, GA: U.S Department of Health and Human Services, Centers for Disease Control and prevention, 2005.

3. Gupta Vipin. Type 2 Diabetes Mellitus in India. South Asia Network for Chronic Disease, New Delhi 2011:1-28.

4. Permutt MA, Wasson J, Cox N. Genetic Epidemiology of Diabetes. Journal of clinical Investigation 2005; 115:14311439.

5. Gul Naheed. Knowladge, Attitude and Practices of type 2 Diabetic Patients. J Ayub Med Coll Abbottabad 2010; 22(3):128-31.

6. Odili VU, Isiboge PD, Eregie A. Patients Knowladge of Diabetes Mellitus in a Nigerian City. Trop J Pharm Res, October 2011;10(5):637-42.

7. Ghosh S. Rajvanshi A and Kishun S. Assessment the patient counseling on quality of life on type-II diabetes mellitus patients. International Journal of Pharma and Bio Sciences, Jul-Sep.2010;3(1):1-6.

8. Ssemaluluu $\mathrm{R}$ and Adome R. Patients knowledge of medication use as an equity issue in health care: Do health workers pay attention to this? EQUINET 2006:1-13. is essential to encourage the patients for regular physical activity, improve dietary habits, lifestyle modification, understanding of disease, to increase medication knowledge and adherence, which helps for improving clinical outcome in diabetic patients as well as other chronic diseases.

\section{CONCLUSION:}

The management of diabetes requires the combination of pharmacological and nonpharmacological measures. The patient education over dietary changes, lifestyle modification, patients understanding over disease, diabetic complications, knowledge of medication and medication adherence help to improve clinical outcome, reduce diabetic complications and which leads to improve patient's quality of life. The overall study concludes that, the proper patient education is essential is to improve clinical outcome diabetic patients.

\section{ACKNOWLEDGEMENT:}

Many thanks to society members and medical staff of Basaveshwar Teaching and General Hospital, Gulbarga for study support. We wish to acknowledge the JDDT Journal.

9. McMurray SD, Johnson G, Davis S, Mc Dougall K. Diabetes education and care management significantly improve patient outcomes in the dialysis unit. Am J Kidney Disease 2002; 40:566-75.

10. Whitley HP, Fermo JD, Ragucci K, Chumney EC. Assessment of patient knowledge of diabetic goals, self-reported medication adherence, and goal attainment. Pharmacy Practice 2006; 4(4):183-190.

11. Palaian S, Acharya LD, Madhava Rao PG, Ravi Shankar P, Nair NM, Nair NP. Knowledge, Attitude and Practice Outcomes: Evaluating the Impact of counseling in Hospitalized Diabetic patients in India. P\&T. July 2006;31(7):383-95.

12. Macaulay AC, Hanusaik N, Delisle DD. Diabetic Education Program in the Mohawk Community of Kahnawake, Quebec. Can Fam Phy sician 1988;34:1591-3.

13. Atak N, Gurkan T, Kose K. The effect of education on knowledge, self management behavior and self efficacy of patients with type 2 diabetes. Australian Journal of Advanced Nursing, 28(2):66-74.

14. Khapre MP, Mudey A, Goyal R. C, Wagh V. Low awareness of diabetes affecting the clinical outcome of patient a crosssectional study conducted in rural tertiary care hospital. Int $\mathbf{J}$ Biol Med Res. 2011;2(3):627-630.

15. Satpute DA, Patil PH, Kuchake VG, Ingle PV, Surana SJ, Dighore PN. Assessment of impact of Patient Counselling, Nutrition and Exercise in patients with Type 2 Diabetes Mellitus. Int.J. PharmTech Res.2009;1(1):1-21 